\title{
New country records of reptiles from Laos
}

\author{
Vinh Quang Luu ${ }^{\dagger, \ddagger}$, Truong Quang Nguyen§,l, Thomas Calameđ, Tuoi Thi Hoang”, Sisomphone \\ Southichack ${ }^{\dagger \dagger}$, Michael Bonkowskil, Thomas Ziegler ${ }^{\ddagger, l}$ \\ † Department of Wildlife, Faculty of Natural Resource and Environmental Management, Vietnam Forestry University, Xuan \\ Mai, Chuong My, Hanoi, Vietnam \\ ‡AG Zoologischer Garten Köln, Riehler Strasse 173, D-50735 Cologne, Germany \\ $\S$ Institute of Ecology and Biological Resources, Vietnam Academy of Science and Technology, 18 Hoang Quoc Viet, Hanoi, \\ Vietnam \\ | Zoological Institute, University of Cologne, Zülpicher Strasse 47b, D-50674 Cologne, Germany \\ I WWF Greater Mekong, House No. 39, Unit 05, Ban Saylom, Vientiane, Lao People's Democratic Republic \\ \# Biodiversity Center, Faculty of Natural Resource and Environmental Management, Vietnam Forestry University, Xuan Mai, \\ Chuong My, Hanoi, Vietnam \\ †† Hin Nam No National Protected Area, Boualapha District, Khammouane Province, Lao People's Democratic Republic
}

Corresponding author: Vinh Quang Luu (qvinhfuv@yahoo.com.au)

Academic editor: Johannes Penner

Received: 27 Oct 2013 | Accepted: 04 Dec 2013 | Published: 10 Dec 2013

Citation: Luu V, Nguyen T, Calame T, Hoang T, Southichack S, Bonkowski M, Ziegler T (2013) New country records of reptiles from Laos. Biodiversity Data Journal 1: e1015. doi: 10.3897/BDJ.1.e1015

\section{Abstract}

Four species of reptiles, of which one is represented by one of its subspecies, are recorded for the first time from Laos: Cyrtodactylus phongnhakebangensis, Lycodon futsingensis, and $L$. ruhstrati, as $L$. ruhstrati abditus, from limestone forests in Khammouane Province and Cyrtodactylus pseudoquadrivirgatus from hill evergreen forest in Salavan Province. These discoveries of lizards and snakes bring the total species number of reptiles to 189 in Laos.

\section{Keywords}

Colubridae, Gekkonidae, distribution, taxonomy, Khammouane Province, Salavan Province 


\section{Introduction}

The knowledge on the diversity of the reptile fauna of Laos has strikingly increased during the recent decades. Stuart (1999) provided the first checklist of 109 reptile species from Laos. Teynié et al. (2004) published an updated checklist of reptiles from southern Laos with a total of 89 recorgnized species. Four years later, Stuart and Heatwole (2008) recorded 13 additional species of colubrid and viperid snakes from the country. The species number of reptiles from Laos was 180 in 2010 (Teynié and David 2010). Since 2010, six new species of reptiles have been described from Laos comprising Cyrtodactylus wayakonei Nguyen, Kingsada, Rösler, Auer \& Ziegler, 2010, C. Iomyenensis Ngo \& Pauwels, 2010, C. teyniei David, Nguyen, Schneider \& Ziegler, 2011, C. pageli Schneider, Nguyen, Schmitz, Kingsada, Auer \& Ziegler, 2011, Lycodon davidi Vogel, Nguyen, Kingsada \& Ziegler, 2012, and Oligodon nagao David, Nguyen, Nguyen, Jiang, Chen, Teynié \& Ziegler, 2012 (Nguyen et al. 2010, Ngo and Pauwels 2010, David et al. 2011, Schneider et al. 2011, Vogel et al. 2012, David et al. 2012). In 2012 and 2013, additional field surveys were conducted in the hill evergreen forest within Xe Sap National Protected Area, Salavan Province, and limestone forests within Hin Nam No National Protected Area, Khammouane Province. Examination of voucher specimens from aforementioned sites revealed the existence of a number of reptile species that have not been known from Laos so far. We herein report four new records of reptiles from the country, comprising two species of Gekkonidae, and one species and one subspecies of Colubridae.

\section{Materials and methods}

Field surveys were conducted by T. Calame in Xe Sap National Protected Area (NPA), Salavan Province in May 2012 and by V. Q. Luu in Hin Nam No NPA, Khammouane Province from April to July 2013 (Figs 1,2). Specimens were collected by hand or snake hook between 19:00-23:00. After taking photographs, specimens were anaesthetized, fixed in $80-85 \%$ ethanol and subsequently stored in $70 \%$ ethanol. Voucher specimens are deposited in the collections of the Institute of Ecology and Biological Resources (IEBR), Hanoi, Vietnam; the National University of Laos (NUOL), Vientiane, Laos; the Vietnam Forestry University (VFU), Hanoi, Vietnam; and the Zoologisches Forschungsmuseum Alexander Koenig (ZFMK), Bonn, Germany. 


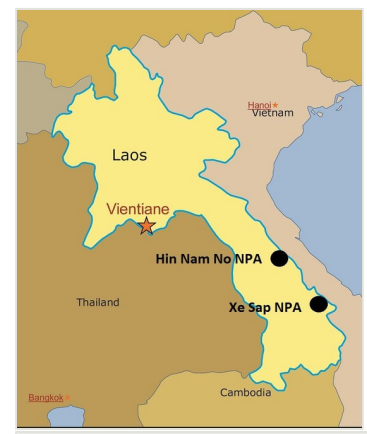

Figure 1.

Map of survey sites in Khammouane and Salavan provinces, Laos.
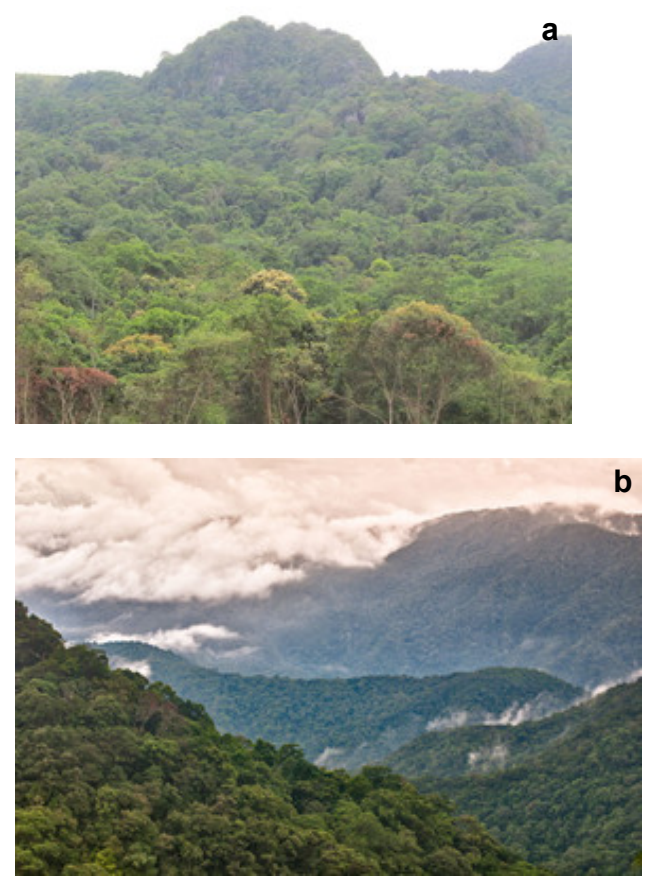

\section{Figure 2.}

Limestone karst forest in Hin Nam No National Protected Area, Khammouane Province and evergreen forest in Xe Sap National Protected Area, Salavan Province, Laos. Photos: V. Q. Luu and T. Calame.

a: Forest in Hin Nam No NPA

b: Forest in Xe Sap NPA

Measurements of specimens were taken with a digital caliper to the nearest $0.1 \mathrm{~mm}$. Abbreviation are as follows: SVL (snout-vent length): from tip of snout to anterior margin of cloaca; TaL (Tail length): from posterior margin of cloaca to tip of tail; TL (total length): SVL 
+TaL. Terminology of morphological characters follows Rösler et al. (2008) for lizards and Vogel et al. (2009) for snakes. Bilateral scale counts were given as left/right.

\section{Taxon treatments}

\section{Cyrtodactylus phongnhakebangensis Ziegler, Rösler, Herrmann \& Vu, 2002}

\section{Material}

a. country: Laos; stateProvince: Khammouane; verbatimLocality: Hin Nam No National Protected Area; verbatimElevation: $180-580 \mathrm{~m}$; verbatimLatitude: $17^{\circ} 15^{\prime}-17^{\circ} 40^{\prime} \mathrm{N}$; verbatimLongitude: $105^{\circ} 43^{\prime}-106^{\circ} 09^{\prime} E$; eventDate: 2013-05-07/2013-06-30; individualCount: 9; sex: 4 males, 5 females; recordedBy: V. Q. Luu; institutionCode: IEBR, VFU, NUOL, ZFMK

\section{Description}

(Fig. 3)
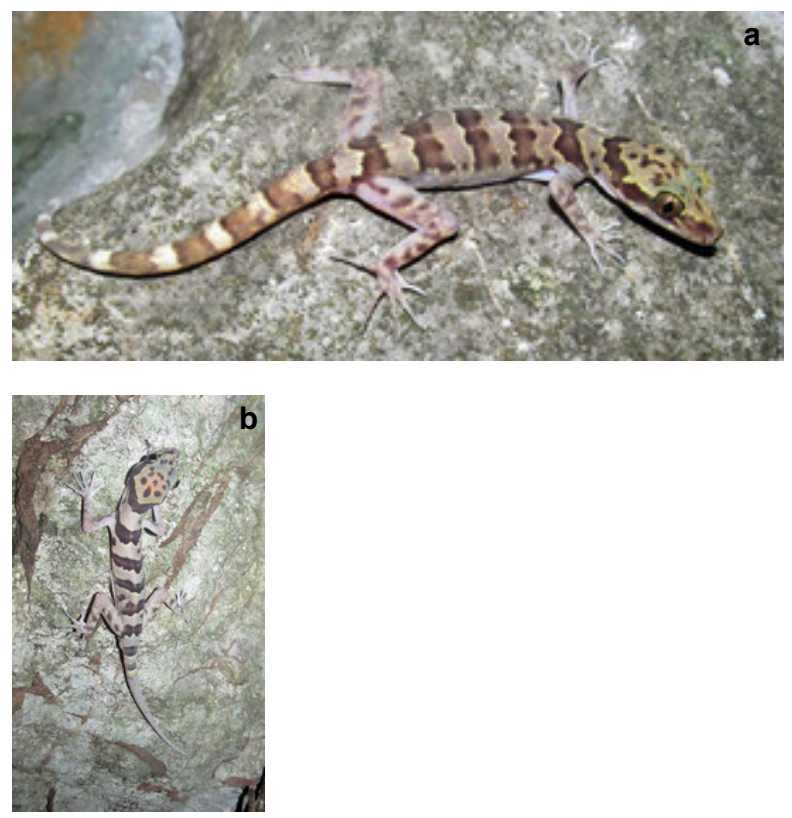

Figure 3.

Cyrtodactylus phongnhakebangensis (female and male) from Hin Nam No National Protected Area, Khammouane Province, Laos. Photos: V. Q. Luu.

a: Female

b: Male 
Specimens examined ( $n=9$ ): Four adult males and five adult females, all collected by V. Q. Luu in Hin Nam No NPA, Khammouane Province: IEBR A.2013.89, adult male, 7 May 2013, from Hang Toi region, Noong Ma Commune $\left(17^{\circ} 17.766^{\prime} \mathrm{N}, 106^{\circ} 08.803^{\prime} \mathrm{E}\right.$, elevation $580 \mathrm{~m}$ a.s.I.); VFU A.2013.1 and NUOL R-2013.2, adult males, 9 June 2013, from Vang Ma No Commune ( $17^{\circ} 30.778^{\prime} \mathrm{N}, 15^{\circ} 49.259^{\prime} \mathrm{E}$, elevation $180 \mathrm{~m}$ a.s.I.); IEBR A.2013.90, adult male, 11 June 2013, from Ban Dou Commune $\left(17^{\circ} 30.385^{\prime} \mathrm{N}, 1^{\circ}\right.$ 49.160'E, elevation 183 m a.s.I.); ZFMK 95235, adult female, 8 May 2013, from Hang Toi region, Noong Ma Commune $\left(17^{\circ} 17.763^{\prime} \mathrm{N}, 106^{\circ} 08.778\right.$ 'E, elevation $555 \mathrm{~m}$ a.s.I.); ZFMK 95236, adult female, 30 May 2013, from Noong Choong Region, Cha Lou Commune $\left(17^{\circ} 20.248^{\prime} \mathrm{N}, 1^{\circ} 5^{\circ} 56.693^{\prime} \mathrm{E}\right.$, elevation $252 \mathrm{~m}$ a.s.I.); VFU A.2013.2A.2013.3, adult females, 9 June 2013 , from Vang Ma No Commune $\left(17^{\circ} 30.778^{\prime} \mathrm{N}, 105^{\circ}\right.$ 49.259'E, elevation 180 m a.s.I.); NUOL R-2013.3, adult female, 11 June 2013, from Ban Dou Commune $\left(17^{\circ} 31.545^{\prime} \mathrm{N}, 105^{\circ} 49.086^{\prime} \mathrm{E}\right.$, elevation 197 m a.s.I.).

Morphological characters: SVL males 83.6-92.5 mm (mean \pm SD $87.9 \pm 4.9 \mathrm{~mm}$ ), females $95-100.6 \mathrm{~mm}$ (mean $\pm \mathrm{SD} 93.8 \pm 5.0 \mathrm{~mm}$ ); tail length (TaL) $101.6 \mathrm{~mm}$ in males, $108.3 \mathrm{~mm}$ in females; head depressed (HL/HW 1.6 in males, 1.5 in females), distinct from neck; snout longer than diameter of ocular (SE/OD 2 in males, 1.9 in females); snout scales small, homogeneous, granular, larger than those in frontal and parietal regions; rostral wider than high with a Y-shape in the middle; supranasals in contact; rostral bordered by first supralabial and nostril on each side; nares oval, surrounded by supranasal, rostral, first supralabial, and two enlarged postnasals; ear oval-shaped; mental triangular; postmental two, enlarged, in broad contact posteriorly; supralabials 9-12; infralabials 8-10; dorsal scales granular to flattened; dorsal tubercles triangular, conical, present on occiput, back and tail base, each surrounded by 8-9 granular scales, in 14-19 irregular longitudinal rows at midbody; ventral scales smooth, medial scales 2-3 times larger than dorsal scales, round, in 35-48 longitudinal rows at midbody; ventrolateral folds present; gular region with homogeneous smooth scales; precloacal groove absent; enlarged femoral scales present; femoral and precloacal pores 36-44 in males, pitted scales $0-28$ in females; postcloacal tubercles 4-6; subcaudals enlarged; dorsal surface of fore and hind limbs with small tubercles; fingers and toes without distinct webbing; lamellae under fourth finger 16-21, under fourth toe 19-22. Coloration in preservative: Ground coloration of dorsal head and back greyish brown with dark spots; nuchal loop distinct, in U-shape, from posterior corner of eye through tympanum to the neck, dark brown, edged in white; body bands between limb insertions four to five, somewhat irregular, dark brown, edged in white; dorsal surface of fore and hind limbs with dark bars; tail brown dorsally with seven to eight light brown bands, edged in white; chin, throat, and belly cream; upper and lower lips with dark brown bars; tail ventrally grey with light dots (determination after Ziegler et al. 2002). 


\section{Distribution}

C. phongnhakebangensis has been known from Phong Nha - Ke Bang National Park, Quang Binh Province, central Vietnam (Nguyen et al. 2009). This is the first record of the species from Laos.

\section{Ecology}

Specimens were found between 19:00 and 22:00 on karst walls, ca. 0.5-3 m above the ground, near cave entrances in limestone forests, at elevations from 180 to $580 \mathrm{~m}$ a.s.I.

\section{Notes}

The Laotian specimens differ from the original description of Ziegler et al. (2002) by having somewhat higher femoral and precloacal pore counts in males (36-44 versus 32-42).

Cyrtodactylus pseudoquadrivirgatus Rösler, Nguyen, Vu, Ngo \& Ziegler, 2008

\section{Material}

a. country: Laos; stateProvince: Salavan; verbatimLocality: Xe Sap National Protected Area; verbatimElevation: $960 \mathrm{~m}$; verbatimLatitude: $16^{\circ} 09.400^{\prime} \mathrm{N}$; verbatimLongitude: $106^{\circ}$ 49.567'E; eventDate: 2012-05-20; individualCount: 2; sex: 2 females; recordedBy: T. Calame; institutionCode: IEBR, NUOL

\section{Description}

(Fig. 4)

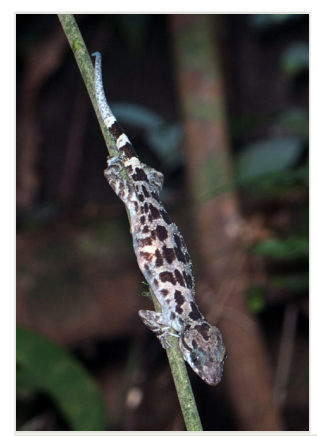

Figure 4.

Cyrtodactylus pseudoquadrivirgatus from Xe Sap National Protected Area, Salavan Province, Laos. Photo: T. Calame. 
Specimens examined $(\mathbf{n}=\mathbf{2}$ ). Two adult females (IEBR A.2013.91 \& NUOL R-2013.4), collected by T. Calame on 20 May 2012 from Xe Sap NPA, Salavan Province $\left(16^{\circ} 09.400^{\prime} \mathrm{N}, 106^{\circ} 49.567^{\prime} \mathrm{E}\right.$, elevation ca. $960 \mathrm{~m}$ a.s.I. $)$.

Morphological characters. SVL 70.7-83.8 mm, tail regenerated (TaL 72.1-72.6 mm); head depressed (HL/HD 1.6), distinguished from neck; loreal region inflated; snout longer than diameter of orbit (SE/OD 1.9); snout scales small, homogeneous, granular, larger than those in frontal and parietal regions; rostral wider than high with a median suture; supranasals separated from each other posteriorly by a pentagonal internasal; rostral bordered by first supralabial and nostril on each side; nares oval, surrounded by supranasal, rostral, first supralabial, and three enlarged postnasals; eyelid fringe with tiny spines posteriorly; ear oval-shaped, somewhat angular; mental triangular, slightly wider than rostral; postmentals in one pair, enlarged, in broad contact posteriorly, bordered by mental anteriorly, first two infralabials laterally, and one pair of distinctly enlarged gular scales posteriorly, which is separated from each other by two small gular scales; supralabials 8-10; infralabials 7-10; dorsal scales granular to flattened; dorsal tubercles triangular, conical, present on occiput, back and tail base, each surrounded by 10-11 granular scales, in 17-18 irregular longitudinal rows at midbody; ventral scales smooth, medial scales 2-3 times larger than dorsal scales, round, subimbricate, in 39-40 longitudinal rows at midbody; ventrolateral folds with interspersed tubercles; gular region with homogeneous smooth scales; precloacal groove absent; enlarged femoral scales and femoral pores absent; precloacal pores 7-9; postcloacal tubercles 2-3; subcaudals slightly enlarged; dorsal surface of fore and hind limbs with tubercles; fingers and toes without distinct webbing; lamellae under fourth finger 16-19, under fourth toe 17-20. Coloration in preservative: Ground coloration of dorsal head and back blackish brown; a narrow curved black stripe from posterior corner of eye, running above tympanum to the neck, interrupted posteriorly; shoulders, dorsal body blotched, irregular from oval to elongate, dark brown; fore and hind limbs with dark bars; dorsal tail grey with dark brown bands; chin, throat, chest and belly brown; ventral tail marked with light and dark bands; upper and lower lips dark brown (determination after Rösler et al. 2008).

\section{Distribution}

This species was previously known in Central Vietnam from Quang Tri province southwards to Kon Tum Province (Rösler et al. 2008). Therefore, our record of $C$. pseudoquadrivirgatus from Salavan Province is the first country record for Laos.

\section{Ecology}

Specimens were found between 19:40 and 20:10 on a small bush stem ca. $40 \mathrm{~cm}$ above the ground, approximately $3 \mathrm{~m}$ away from a rocky stream. The surrounding habitat was hill evergreen forest at an elevation of $960 \mathrm{~m}$ a.s.l. Within the hill evergreen forest in western Xe Sap NPA the canopy is characterized, in many areas, by the conspicuous presence of emergents of the restricted range conifer Pinus dalatensis. 


\section{Lycodon futsingensis (Pope, 1928)}

\section{Material}

a. country: Laos; stateProvince: Khammouane; verbatimLocality: Hin Nam No National Protected Area; verbatimElevation: $581 \mathrm{~m}$; verbatimLatitude: $17^{\circ} 17.499^{\prime} \mathrm{N}$; verbatimLongitude: $106^{\circ} 10.606$ 'E; eventDate: $2013-05-14$; individualCount: 1 ; sex: female; recordedBy: V. Q. Luu; institutionCode: VFU

\section{Description}

(Fig. 5)
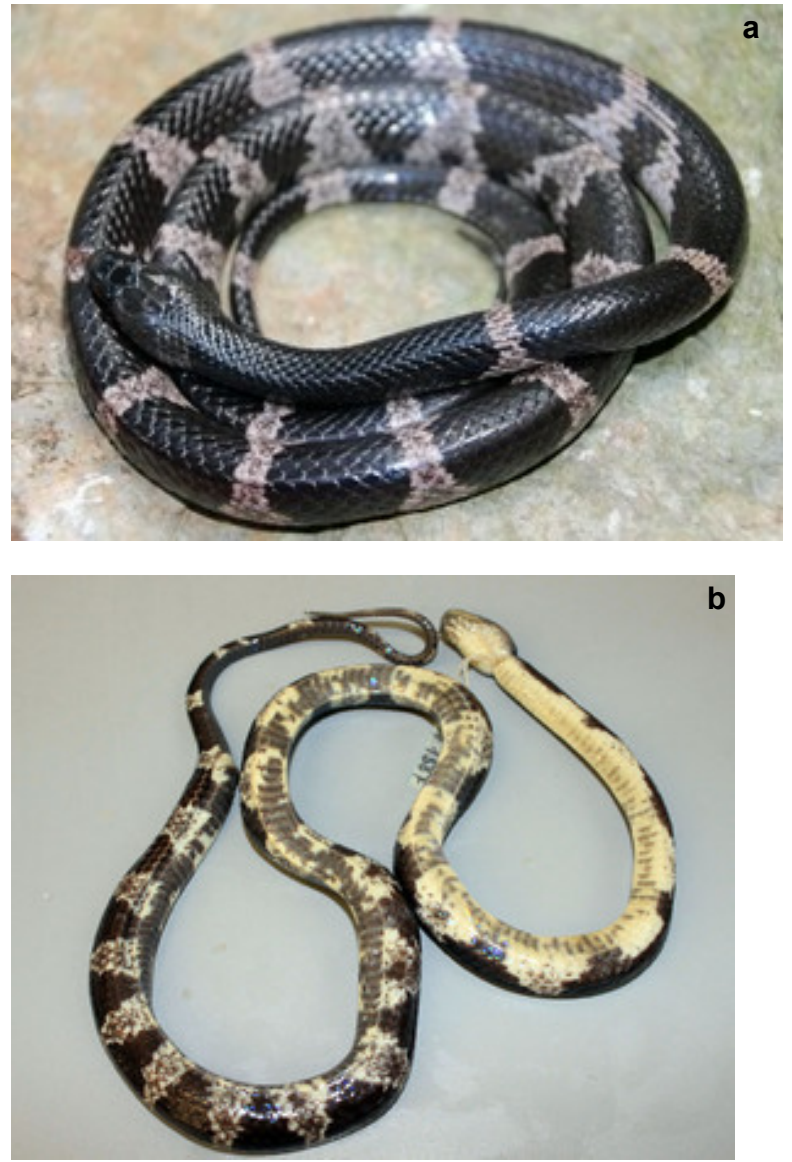

Figure 5.

Lycodon futsingensis from Hin Nam No National Protected Area, Khammouane Province, Laos. Photos: V. Q. Luu.
a: Dorsal view
b: Ventral view 
Specimen examined $(\mathbf{n}=\mathbf{1})$. VFU A.2013.4, adult female, collected by V. Q. Luu on 14 May 2013 from Noong Ma Commune, Boualapha District, Khammouane Province $\left(17^{\circ} 17.499^{\prime} \mathrm{N}, 106^{\circ} 10.606^{\prime} \mathrm{E}\right.$, elevation 581 m a.s.I.), within Hin Nam No NPA.

Morphological characters. Total length (TL) $760 \mathrm{~mm}$ (SVL 603mm, TaL $157 \mathrm{~mm}$ ); body subcylindrical; head moderately distinguished from neck, rather flattenned; snout elongate, projecting anteriorly beyond lower jaw; pupil vertically elliptic; maxillary teeth 12/12; rostral distinctly broader than high, partly visible from above; internasals as wide as long, not in contact with loreal; prefrontal less than half length of frontal; frontal hexagonal; parietals longer than wide; nasal paired; loreal 1/1, not in contact with orbit; supralabials $8 / 8$, third to fifth touching the eye, seventh largest; infralabials $9 / 9$, first to fifth bordering chin shields; preocular $1 / 1$; postoculars $2 / 2$, bodering anterior temporals; anterior temporals $2 / 2$, posterior temporals $2 / 2$; dorsal scale rows $17-17-15$, smooth; ventrals 209; subcaudals 79, paired; cloacal undivided. Coloration in preservative: Dorsal surface greyish-black with 19-21 grey rings on body and 9 cross-bands on tail; belly cream, anterior part uniform, speckled posteriorly, under tail dark (determination after Vogel et al. 2009, Vogel and David 2010).

\section{Distribution}

Lycodon futsingensis has been reported from southern China and northern Vietnam (Vogel et al. 2009). This is a new record of the species from Laos and it is approximately about $20 \mathrm{~km}$ far from the nearest record of this species in Phong Nha Ke Bang National Park, Quang Binh Province, Vietnam.

\section{Ecology}

The adult female was collected at ca. 21:30 while moving on the forest floor, near a slow running stream. The surrounding habitat was karst forest at elevation of $581 \mathrm{~m}$ a.s.l.

\section{Lycodon ruhstrati abditus Vogel, David, Pauwels, Sumontha, Norval, Hendrix, Vu \& Ziegler, 2009}

\section{Material}

a. country: Laos; stateProvince: Khammouane; verbatimLocality: Hin Nam No National Protected Area; verbatimElevation: $556 \mathrm{~m}$; verbatimLatitude: $17^{\circ} 17.648^{\prime} \mathrm{N}$; verbatimLongitude: $106^{\circ} 10.053^{\prime} E$; eventDate: $2013-05-14$; individualCount: 1 ; sex: male; recordedBy: V. Q. Luu; institutionCode: VFU 


\section{Description}

(Fig. 6)
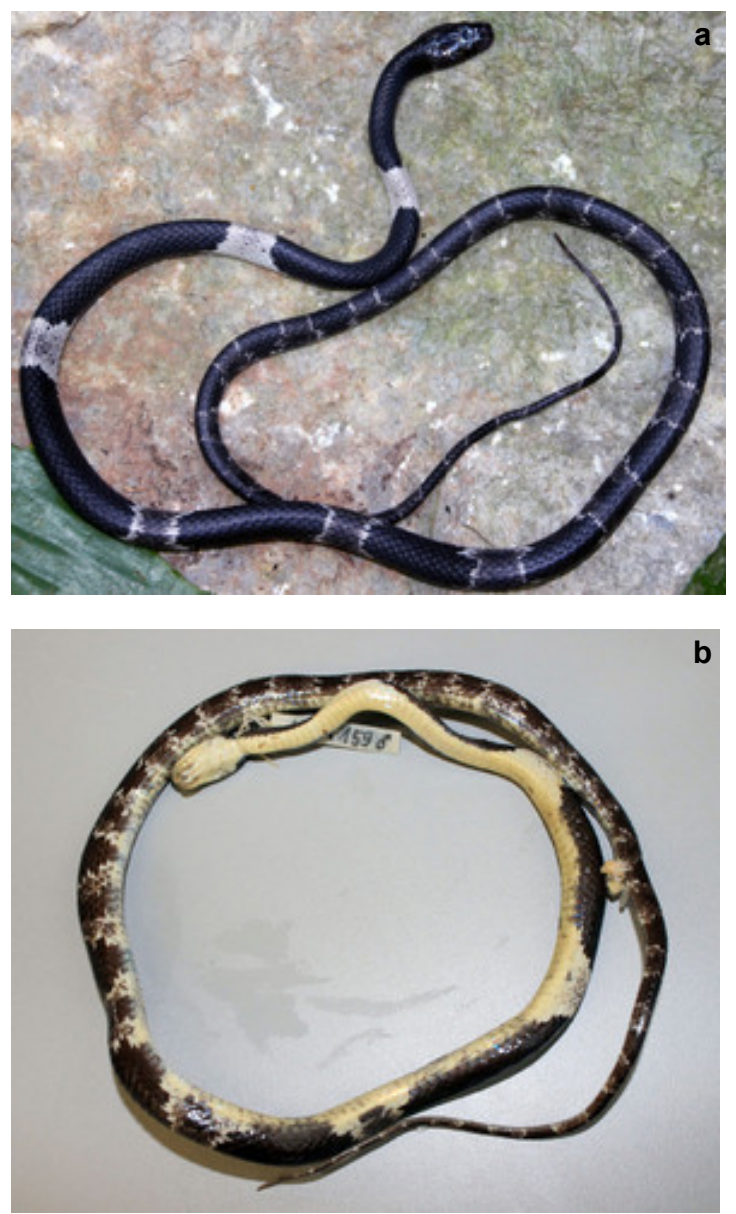

Figure 6.

Lycodon ruhstrati abditus from Hin Nam No National Protected Area, Khammouane Province, Laos. Photos: V. Q. Luu.
a: Dorsal view
b: Ventral view

Specimen examined $(\mathbf{n}=\mathbf{1})$. VFU A.2013.5, adult male, collected by V. Q. Luu on 14 May 2013 from Pa Rang region, Noong Ma Commune, Boualapha District, Khammouane Province $\left(17^{\circ} 17.648^{\prime} \mathrm{N}, 106^{\circ} 10.053^{\prime} \mathrm{E}\right.$, elevation $556 \mathrm{~m}$ a.s.l.), within Hin Nam No NPA. 
Morphological characters. Total length (TL) $665 \mathrm{~mm}$ (SVL $520 \mathrm{~mm}$, TaL $145 \mathrm{~mm}$ ); body elongate; head moderately distinct from neck, rather flattened; snout projecting anteriorly beyond lower jaw; pupil vertically oval; tail tapered and thin; maxillary teeth 12/12; snout scale broad; rostral distinctly broader than high, partly visible from above; internasals large, pentagonal, not in contact with loreal; prefrontal more than half length of internasal, subrectangular, wider than long, not entering orbit; frontal hexagonal, narrowed posteriorly; parietals longer than wide; nasal paired; loreal $1 / 1$, small, pentagonal, not bordering the eye; supralabials $8 / 8$, third to fifth in contact with the eye, sixth largest; infralabials 10/10, first to fifth bordering chin shields; preocular 1/1; postoculars $2 / 2$, bordering anterior temporal; anterior temporals $2 / 2$; posterior temporals 3/3; dorsal scale rows 17-17-15; five middorsal scales keeled, the outer rows usually smooth; ventrals 224; subcaudals 96 , paired; cloacal single. Coloration in preservative: Dorsal surface greyish or blackish, with white and cream cross-bars, 17 on the body, increasing the size at the bottom of each light cross-bands, best marked anteriorly, and becoming dim posteriorly; belly cream, progressively but not extensively speckled with dark grey on the posterior edges of the ventral scales; upper tail as the posterior body, tail rings cream and extending towards the under part of the tail (determination after Vogel et al. 2009, Ziegler et al. 2007).

\section{Distribution}

Lycodon ruhstrati has been known from Taiwan, China and northern Vietnam: L. $r$. ruhstrati is endemic to Taiwan and the range of $L$. $r$. abditus is widespread in the mainland of China and Vietnam (see Vogel et al. 2009). Our finding represents the first record of the species as well as the subspecies, L. r. abditus, from Laos and it is approximately about $20 \mathrm{~km}$ far from the type locality of the subspecies in Phong Nha Ke Bang National Park, Quang Binh Province, Vietnam.

\section{Ecology}

The specimen of $L$. ruhstrati abditus was found at 11:00 while moving through a forest path. The surrounding habitat was karst forest at the elevation of $556 \mathrm{~m}$ a.s.l.

\section{Notes}

The specimen from Laos differs from the description of Vogel et al. (2009) in having fewer cross-bands on the body (17 versus 19-43).

\section{Discussion}

The recent discoveries of Cyrtodactylus phongnhakebangensis and $C$. pseudoquadrivirgatus in Laos bring the species number of the genus Cyrtodactylus known from that country to ten. This is still a low number compared with the Cyrtodactylus 
diversity from neighbouring Vietnam (which currently comprises 29 species, see Ziegler et al. 2013). In central Vietnam's Phong Nha - Ke Bang National Park two other bent-toed geckos, C. cryptus Heidrich, Rösler, Vu, Böhme \& Ziegler, 2007 (Heidrich et al. 2007) and C. roesleri Ziegler, Nazarov, Orlov, Nguyen, Vu, Dang, Dinh \& Schmitz, 2010 (Ziegler et al. 2010), are known to occur sympatrically with C. phongnhakebangensis (Loos et al. 2012). In Hin Nam No NPA, our observation also supports the finding of Loos et al. (2012) about niche segregation of Cyrtodactylus species. Both $C$. roesleri and $C$. phongnhakebangensis were found on karst cliffs in the same habitat (Fig. 7). In Laos, C. roesleri was previously recorded from Phou Hin Boun in Khammouane Province by Teynié and David (2010). This is the first record of the species from Hin Nam No NPA. The new records of Lycodon futsingensis, and L. ruhstrati abditus from Khammouane Province increase the species number of snakes in Laos to 107. However, the diversity of reptiles in Laos is still poorly studied, particular in Hin Nam No NPA. In the bordering Phong Nha - Ke Bang National Park in Vietnam, Luu et al. (2013) recently provided a list of 101 reptile species including 15 new species and one new subspecies that have been described only from this site since 2000 . Therefore, further field research is required to explore the actual herpetofaunal diversity of the largest karst formation in central Laos.
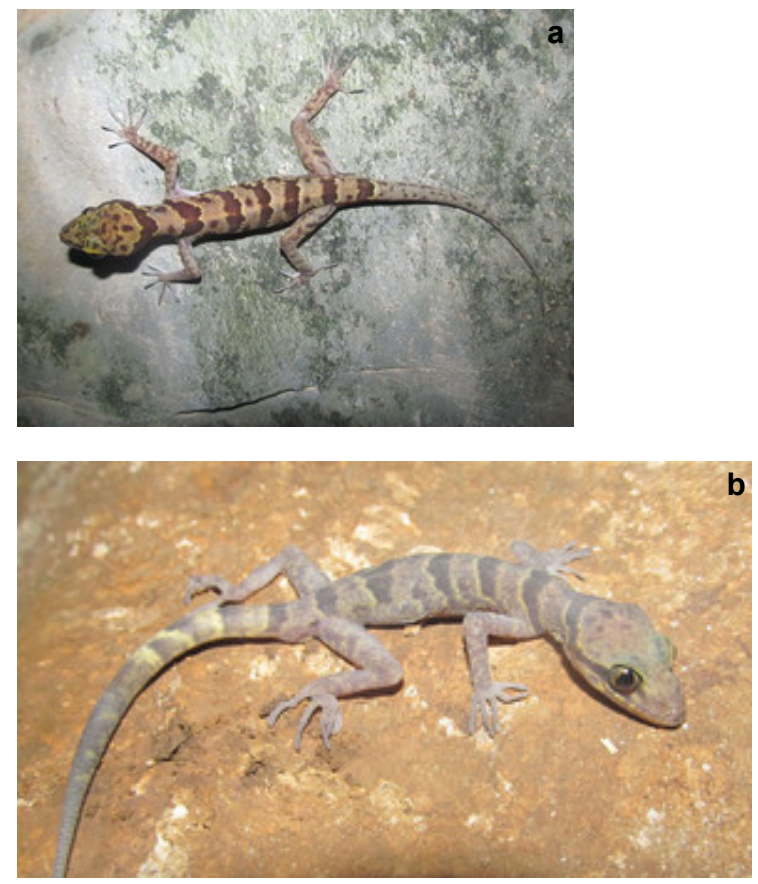

Figure 7.

Two sympatric species, Cyrtodactylus phongnhakebangensis and C. roesleri, in situ on limestone walls in Hin Nam No National Protected Area, Khammouane Province, Laos. Photos: V. Q. Luu.

a: Cyrtodactylus phongnhakebangensis

b: Cyrtodactylus roesleri 


\section{Acknowledgements}

We are grateful to Ass. Prof. Dr. Sengdeuane Wayakone, Ass. Prof. Dr. Houngphet Chanthavong, Ass. Prof. Dr. Khamla Phanvilay, Dr. Bounthob Praxaysombath, Mr. Khanthaly Khamphilavong, Mr. Saly Sitthivong (NUOL, Vientiane), Dr. Thomas Gray (WWF Greater Mekong), Mr. Thanousone Homsaysombath, Mr. Kieusomphone Thanabuaosy, and Mr. Thidtavanh Suliyavong (Khammouane) for supporting our field research in Laos. Export of collected specimens was done due to the export permits Number 103/13 and 105/13 signed by the CITES Management Authority of Lao PDR. V.Q. Luu thanks Prof. Dr. Chuong Van Pham, Prof. Dr. Nha The Nguyen, and Ass. Prof. Dr. Doi The Bui (VFU, Hanoi) for supporting his work. Field work in Khammouane Province was funded by The Rufford Foundation for V. Q. Luu. Work in the Xe Sap NPA forms part of the CarBi Project of WWF Greater Mekong and the government of Laos PDR through funds provided by WWF Germany and KfW Bankengruppe. Additional support for T. Calame came from grants to Global Wildlife Conservation from the Margot Marsh Biodiversity Fund and Ocean Park Conservation Foundation, Hong Kong, China. Research of V. Q. Luu in Germany is funded by the Ministry of Education and Training of Vietnam (MOET, Project 911) and the German Academic Exchange Service (DAAD). Research of T.Q. Nguyen in Germany is funded by the Alexander von Humboldt Stiftung/Foundation (VIE 114344).

\section{References}

- David P, Nguyen TQ, Schneider N, Ziegler T (2011) A new species of the genus Cyrtodactylus Gray, 1827 from central Laos (Squamata: Gekkonidae). Zootaxa 2833: 29-40. [In English].

- David P, Nguyen TQ, Nguyen TT, Jiang K, Chen T, Teynié A, Ziegler T (2012) A new species of the genus Oligodon Fitzinger, 1826 (Squamata: Colubridae) from northern Vietnam, southern China and central Laos. Zootaxa 3498: 45-62. [In English].

- Heidrich A, Rösler H, Vu TN, Böhme W, Ziegler T (2007) Another new Cyrtodactylus (Squamata: Gekkonidae) from Phong Nha-Ke Bang National Park, central Truong Son, Vietnam. Zootaxa 1445: 35-48. [In English].

- Loos J, Wehrden HV, Dang KN, Ziegler T (2012) Niche segregation in Microhabitat use of three sympatric Cyrtodactylus in the Phong Nha-Ke Bang National Park, Central Vietnam. Herpetological Conservation and Biology 7 (1): 101-108. [In English].

- Luu VQ, Nguyen TQ, Pham CT, Dang KN, Vu TN, Miskovic S, Bonkowski M, Ziegler T (2013) No end in sight? Further new records of amphibians and reptiles from Phong Nha-Ke Bang National Park, Quang Binh Province, Vietnam. Biodiversity Journal 4 (2): 285-300. [In English].

- Ngo TV, Pauwels OS (2010) A new cave-dwelling species of Cyrtodactylus Gray, 1827 (Squamata: Gekkonidae) from Khammouane Province, southern Laos. Zootaxa 2730: 44-56. [In English].

- Nguyen SV, Ho CT, Nguyen TQ (2009) Herpetofauna of Vietnam. Edition Chimaira. Frankfurt am Main, 768 pp. [In English].

- Nguyen TQ, Kingsada P, Rösler H, Auer M, Ziegler T (2010) A new species of Cyrtodactylus (Squamata: Gekkonidae) from northern Laos. Zootaxa 2652: 1-16. [In English]. 
- Rösler H, Vu TN, Nguyen TQ, Ngo TV, Ziegler T (2008) A new Cyrtodactylus (Squamata: Gekkonidae) from Central Vietnam. Hamadryad 33 (1): 48-63. [In English].

- Schneider N, Nguyen TQ, Schmitz A, Kingsada P, Auer M, Ziegler T (2011) A new species of karst dwelling Cyrtodactylus (Squamata: Gekkonidae) from northwestern Laos. Zootaxa 2930: 1-21. [In English].

- Stuart BL (1999) Amphibians and reptiles. In: Duckworth JW, Salter RE, Khounboline K (Eds) Wildlife in Lao PDR: 1999 Status Report. IUCN-The World Conservation Union / Wildlife Conservation Society / Centre for Protected Areas and Watershed Management., Vientiane, 43-67 pp. [In English].

- Stuart BL, Heatwole H (2008) Country records of snakes from Laos. Hamadryad 33: 97-106. [In English].

- Teynié A, David P (2010) Voyages naturalistes au Laos-Les Reptiles. Editions Revoir. Nohanent (France), 315 pp. [In French].

- Teynié A, David P, Ohler A, Luanglath K (2004) Note on a collection of Amphibians and Reptiles from Southern Laos, with a discussion of occurrence of Indo-Malayan species. Hamadryad 29 (1): 33-62. [In English].

- Vogel G, David P (2010) A new species of the genus Lycodon (Boie, 1826) from Yunnan Province, China (Serpentes: Colubridae). Bonn zoological Bulletin 57 (2): 289-296. [In English].

- Vogel G, Nguyen TQ, Kingsada P, Ziegler T (2012) A new species of the genus Lycodon Boie, 1826 from Laos (Squamata: Colubridae). North-Western Journal of Zoology 8: 344-352. [In English].

- Vogel G, David P, Pauwels OS, Sumontha M, Norval G, Hendrix R, Vu TN, Ziegler T (2009) A review of Lycodon ruhstrati (Fischer 1886) auctorum (Squamata Colubridae), with the description of a new species from Thailand and a new subspecies from the Asian mainland. Tropical Zoology 22: 131-182. [In English].

- Ziegler T, Phung TM, Le MD, Nguyen TQ (2013) A new Cyrtodactylus (Squamata: Gekkonidae) from Phu Yen Province, southern Vietnam. Zootaxa 3686: 432-446. [In English]. DOI: 10.11646/ zootaxa.3686.4.2

- Ziegler T, Rösler H, Herrmann HW, Vu TN (2002) Cyrtodactylus phongnhakebangensis sp. n., ein neuer Bogenfingergecko aus dem annamitischen Karstwaldmassiv, Vietnam. Herpetofauna 24: 11-25. [In German].

- Ziegler T, Hendrix R, Vu TN, Vogt M, Forster B, Dang KN (2007) The diversity of a snake community in a karst forest ecosystem in the central Truong Son, Vietnam, with an identification key. Zootaxa 1493: 1-40. [In English].

- Ziegler T, Nazarov R, Orlov N, Nguyen TQ, Vu TN, Dang KN, Dinh TH, Schmitz A (2010) A third new Cyrtodactylus (Squamata: Gekkonidae) from Phong Nha - Ke Bang National Park, Vietnam. Zootaxa 2413: 20-36. [In English]. 